\title{
Does Controlling for Comorbidity Matter? DSM-Oriented Scales and Violent Offending in Chicago Youth
}

\author{
Denise Paquette Boots ${ }^{1 *}$ and Jennifer Wareham ${ }^{2}$ \\ ${ }^{1}$ University of Texas at Dallas, Program in Criminology, Richardson, Texas \\ ${ }^{2}$ Department of Criminal Justice, Wayne State University, Detroit, Michigan
}

: : : : : : : : : : : : : : : : : : : : : : : : : : : : : : : $: 1: 1:$

Mental health problems have long been linked to antisocial behaviors. Despite an impressive body of literature demonstrating this relationship and claims that comorbidity matters, few studies examine comorbidity using multiple distinct mental health indicators, with most studies instead adopting single or composite mental health measures. This study tested separate and comorbid effects of five DSM-oriented mental health issues on self-reported violence using a community-based sample of Chicago youths from the Project on Human Development in Chicago Neighborhoods. Moreover, it utilized both primary caregiver and youth self-reports of psychopathology across four developmental stages of childhood and adolescence. When examined separately, the results indicated affective/depressive, anxiety, attention deficit hyperactivity, and oppositional defiant/antisocial personality problems independently predicted violence. When considering comorbidity, however, only oppositional defiant and antisocial personality problems significantly predicted violence at any stage, regardless of informant type. Implications for future studies and policy are discussed. Aggr. Behav. 35:1-17, 2010. (C) 2010 Wiley-Liss, Inc.

: : : : : : : : : : : : : : : : : : : : : : : : : : : : : :

Keywords: mental health; youth violence; DSM-oriented scales; developmental criminology; PHDCN

\section{INTRODUCTION}

Since the early 1990s, scholarly works have produced an impressive body of knowledge subsumed under a developmental criminology framework that "holds the potential for refining our understanding of how risk factors may work at different ages and stages within the lives of children and their families to predict offending into the adult years" [Leschied et al., 2008, $\mathrm{p}$ 437]. With the advent of more prospective, longitudinal community-based study designs that increasingly focus on young children, preadolescents, and atrisk youth, a growing body of evidence is mounting regarding the presence of certain risk factors and early life experiences in predicting later antisocial behaviors, and in particular violence [Farrington, 2000]. This developmental context is especially meaningful when considering the onset, continuity, and persistence of problem behaviors and their impact on pathways of violence in youth, as it allows for a comparison of normative vs. non-normative behaviors that are age and gender appropriate over each stage of the lifecourse [Bartusch et al., 1997]. The advancement of developmental research is critical to both theory building and evidence-based public health policymaking, as "understanding which risk and protective factors apply to which problem behaviors, and whether particular risk and protective factors can best explain some but not other problem behaviors, is essential for the formulation of theories that form the basis of interventions" and prevention [Loeber et al., 1998, p 2]. If there are indeed multiple pathways that involve different causal processes across subgroups of violent individuals, as developmental criminologists argue, then it is "unlikely that a single approach to intervention will be equally effective across the different pathways" [Frick, 2000, p 498].

Largely based on developmental prospective studies, global efforts are currently under way that target the amelioration and prevention of interpersonal violence via a public health paradigm of risk [France and Utting, 2005], with mental illness emerging as a key variable of interest in pathways to aggressive behaviors [Loeber, 2004]. A good

\footnotetext{
*Correspondence to: Denise Paquette Boots, University of Texas at Dallas, Program in Criminology, 800 W. Campbell Road GR 31, Richardson, TX 75080. E-mail: deniseboots@utdallas.edu
}

Received 23 July 2009; Revised 29 November 2009; Accepted 24 December 2009

Published online in Wiley InterScience (www.interscience.wiley.com). DOI: $10.1002 / \mathrm{ab} .20338$ 
number of longitudinal studies to date have focused solely on either the development or prevalence of mental disorders in children [Angold and Costello, 1993; Kessler et al., 2009; Mendelson et al., 2008] or on the onset and persistence of antisocial and deviant behaviors in boys [Boots, 2008; Capaldi and Stoolmiller, 1999; Loeber et al., 1998]. Relatively few studies, however, have simultaneously and prospectively examined measures regarding the onset of mental disorders in both boys and girls and violent behaviors [Conduct Problems Prevention Research Group, 2002]. An even smaller proportion of studies have utilized prospective, community-based data to investigate the casual mechanisms of aggression using representative populations of youth across different age cohorts [Boots and Wareham, 2009]. Moreover, given the wealth of empirical research that exists concerning specific mental health problems and links with violent crime and delinquency, it is striking that the majority of developmental studies examine only one or two clinical levels or types of mental disorder at a time (e.g., Conduct Disorder (CD) and Oppositional Defiant Disorder) or, conversely, focus on groups of mental health problems under a larger categorical framework (e.g., mood disorders or disruptive disorders), but ignoring the influence of other co-occurring mental health disorders that may also be related to antisocial behaviors. Alternatively, another empirical body of research has utilized internalizing or externalizing constructs of related mental health symptoms to group psychopathological problems by their common features, in an effort to study the link between psychopathology and violence [see e.g., Bardick and Bernes, 2008; Dennis et al., 2006; Troop-Gordon and Ladd, 2005].

Although these studies have as a whole furthered our understanding of the salience of mental illness as a risk factor for violent behavior, each of these methodological approaches has limitations. That is, such studies limit our understanding of the influence of mental health on violent outcomes because they either (a) examine the relative influence of a singular mental health condition without controlling for multiple forms of psychopathology, which might render the effects on violence insignificant, or (b) examine composite measures of related disorders, which do not allow for the identification of specific mental problems and symptoms. Studies using composite or singular mental health risk factors to predict future antisocial behavior diminish our ability to inform treatment and prevention efforts. More specifically, a study using a composite measure of mental health problems may demonstrate a significant association with future violence, but it offers little insight into which particular symptoms of mental health problems are most strongly associated with violence. Consequently, treatment implications from such a study will be too broad to be efficacious. Alternatively, a study relying on a singular construct of mental health problems (e.g., Oppositional Defiance or Depression) may demonstrate a significant association with future violence, but it offers very narrow insight into treatment and prevention. Treatment implications from studies of singular mental health risk factors for antisocial behavior fail to consider the interaction of other mental health symptomology; and, therefore, run the risk of offering treatment based on incomplete and/or inaccurate projections of outcomes. Also important is the fact that while the vast majority of studies ignore subclinical levels of mental illness; those that do include such levels tend to focus on the link between subclinical disorders and other full psychiatric disorders and fail to apply these scales to investigations on the etiology of violence [Lewinsohn et al., 2004]. Thus, although the issue of "comorbidity" is one that from the outset appears to receive a respectable amount of attention in the literature [Angold et al., 1999], differences in designs and methodologies across these empirical works leave much unresolved concerning the relationship and salience of mental health and offending from a developmental perspective. In comparison, comorbid models that include prospective, gender- and ageappropriate measures of multiple childhood and adolescent mental health problems associated with antisocial behavior allow for a determination of which disorders best predict future violence, but controlling for other forms of psychopathology.

There are critical public policy and substantive reasons to extend the way we have explored mental health problems to date. First, public concern grows with the increasing number of youth with destructive and debilitating forms of psychopathology entering the criminal justice system on serious charges [Grisso, 2008; Teplin et al., 2006]. Second, research indicates that the prevalence of serious disorders with onset in childhood and adolescence, such as Oppositional Defiance, Attention Deficit/Hyperactivity, Anxiety, and Affective Disorders, is rising and constitutes a serious public health concern [Loeber and Farrington, 2000; US Department of Health and Human Services, 1999]. Third, there is a need to study mental health disorders using innovative and dimensional measurement techniques when examining children and adolescents with mental health impairment [Widiger and Clark, 2000]. 
In an effort to address these concerns, this study methodologically adopts more continuous and dimensional forms of mental health disorders called DSM-oriented scales, rather than relying on purely categorical yes or no diagnoses commonly used in practice and empirical studies of youth [Achenbach and Rescorla, 2001]. Achenbach and Rescorla [2001] adopted a "top-down" approach (i.e., directly derived from the diagnostic criteria in the DSM for a particular disorder) in creating these scales, with a team of international experts first rating the consistency of each of the scale items as compared with the respective DSM diagnosis; only those items that were rated very consistent with the diagnostic categories by a plurality of mental health experts were subsequently included to create six DSMoriented scales, which were then normed with national samples. Extensive testing of the psychometric properties of these scales has shown high levels of validity, good internal consistency (mean $\alpha$ ranging from .75 to .84 with an overall mean of .80 ), test-retest reliability $(r=.78-.88$ with overall mean of .83), and goodness of fit for child and parent instruments via confirmatory factor analysis [see e.g., Achenbach and Rescorla, 2001; Achenbach et al., 2003]. These types of measures are a practical tool for clinicians to be aware of because children or adolescents who do not have enough symptoms to reach a clinical diagnosis may still have enough differences, when compared with their "normal" peers, to suggest that their problem behaviors are at a level warranting treatment. The DSM-oriented scales allow for a distinction between normal, borderline, and clinical levels of mental health problems not possible with strictly categorical diagnoses. These dimensional scales have significant utility for criminal justice personnel and clinicians while simultaneously offering insights into the distinctions along the continuum of psychopathology that are most contributory to violent pathways across age and gender. Thus, although each of these disorders has been connected to varying degrees in the literature to both other mental health disorders and violent and aggressive behaviors, the mechanisms and specific influence of these disorders singly and within comorbid models over various stages of childhood and adolescence remain poorly understood [Boots, 2008; Elbogen and Johnson, 2009; Loeber, 2004].

Although limitations here do not allow for an exhaustive review of the body of scholarship on mental health disorders and aggression over the lifecourse, each of the childhood DSM-oriented problems included here represent common mental health issues in disturbed youngsters and have been empirically linked to some extent with future aggressive behaviors. These problem behaviors include Oppositional Defiant Problems [ODP; Langbehn et al., 1998; Loeber, 2004; Vermeiren, 2003], Attention Deficit/Hyperactivity Problems [ADHP; Farrington, 2005; Frick, 1998; Moffitt, 1990; Pliszka, 1998], Anxiety Problems [Connor, 2002; Russo and Beidel, 1994; Vermeiren, 2003], Affective Problems [Biederman et al., 2001; Goldstein et al., 2005; Knox et al., 2000; Teplin, 2001], and Somatic Problems [Bailey et al., 2005; Crofford, 2007; Piko et al., 2006]. The sixth and final childhood DSM-oriented scale constructed by Achenbach, or Conduct Disorder, is not utilized in this study. This scale was purposefully omitted in this model owing to multicollinearity and tautology issues raised when examining youth violence outcomes, as CD is characterized by four groupings of aggressive behavior which violate societal rules and the rights of others (including physical violence to other people or animals, weapon use to commit other crimes or threaten victims, forced sexual activity, etc.). However, because CD plays a major role in the literature on mental health and aggression/ violence pathways and is a common subsequent diagnosis for children with ODP [American Psychiatric Association, 2000; Lahey and Loeber, 1994; Loeber et al., 1991], it is included in the present discussion when applicable, as it relates to both the continuity and stability of disruptive behaviors and the developmental progression of co-occurring mental health problems into adulthood [see Frick, 1998; Hill and Nathan, 2008]. Similarly, it should be noted that while substance abuse and use disorder has a wellknown and robust association with other forms of mental illness and antisocial behaviors [see e.g., Arseneault et al., 2000; Loeber et al., 1998], we were precluded from operationalizing such measures because Achenbach and associates have not created a DSM-oriented scale for this type of disorder in youth.

Recent advances in longitudinal designs in developmental criminology have led to data collection on mental health functioning within young children and adolescent populations using data from multiple informants nested within community-based populations [Arseneault et al., 2000; Tremblay et al., 1995]. Such data allow for greater generalizability and comparisons across empirical findings. In an effort to contribute further to our understanding of the role that mental health dysfunction plays in lifecourse outcomes, such as violence, this study utilizes prospective data across multiple cohorts participating in the Project on Human Development in Chicago 
Neighborhoods (PHDCN), a large community-based sample of Chicago youth, to examine the role of individual and comorbid mental health problems in later violent behaviors. The design and large number of diverse variables collected prospectively in the PHDCN provides a rich dataset to test such relationships. This study is among the first to apply this innovative methodology to the PHDCN [Boots and Wareham, 2009], and takes an exploratory approach to explore a number of specific research questions, including: Which of the five DSM-oriented mental health problems individually predict violent offending over various stages of childhood and adolescence, when controlling for sociodemographic factors and earlier offending behaviors? If individual disorders emerge as significant predictors of violence, do these mental health problems remain statistically significant predictors once comorbidity with other mental health problems is considered? Last, do these effects remain constant when looking across both parent and youth reports of psychopathology?

This work is expanded further by Boots [2008] who used Pittsburgh Youth Study (PYS) data to examine the relationship between mental health and offending in the youngest cohort of PYS boys from middle childhood through to late adolescence. As such, this study extends the literature by comparing the ability of both individual and comorbid models of serious mental health problems in predicting violence among boys and girls across distinct developmental stages using community-based data from multiple informants participating in the PHDCN. To fully test these research questions, each of these DSM-oriented scales are included in a model by age chunk and then by informant to determine both their independent and combined influence on youth violence outcomes. Although this study requires a sizeable number of tests to be performed within the same sample, such modeling techniques are necessary to examine independent and simultaneous mental health influences when considering whether comorbidity matters.

\section{METHODS}

\section{Sample}

This study relies on secondary data from the first two waves of the Longitudinal Cohort Study from the PHDCN. Although three waves of PHDCN data are available, several items used to create the DSM-oriented scales were eliminated in the Wave 2 and Wave 3 data collection. Therefore, these analyses are limited to examining the effects of
Wave 1 indicators on Wave 2 outcomes. The Longitudinal Cohort Study collected extensive inhome and assessment data from parents (primary caregivers) and youths for seven age cohorts (birth, 3, 6, 9, 12, 15, and 18). Participants were selected utilizing a three-stage stratified sampling design. First, the city of Chicago was subdivided into 343 neighborhood clusters, which were stratified by seven levels of racial/ethnic mix and three levels of socioeconomic status (SES). Then, 80 neighborhood clusters were randomly selected for residential sampling. Neighborhood clusters for predominately Hispanic and high SES, Hispanic/Black mixed and high SES, and predominately White and low SES were unavailable; therefore, the PHDCN sample lacks representation for these areas. Finally, dwelling units were randomly selected, proportionate to size, from the 80 neighborhood clusters. The result was a sample representative of the Chicago area with respect to racial/ethnic and socioeconomic distribution at the neighborhood level.

The Longitudinal Cohort Study ${ }^{1}$ of individuals selected by the PHDCN was administered at three waves over a 6-year period: Wave 1 in 1995-1997 (75\% average response rate), Wave 2 in 1997-2000 ( $86 \%$ average response rate), and Wave 3 in 2000-2001 (78\% average response rate). In this study, Wave 1 and Wave 2 data are used for youths who were at least 7 years old (from cohorts 6 through 18) at Wave 1. Borrowing conceptually from the developmental and child psychology literature, these data were divided into four age periods that reflect different stages of human development during childhood and adolescence. These developmental stages (referred to henceforth as "chunks") include middle childhood for ages 7-9 (chunk 1; $M=8.64$ years old), late childhood for ages $10-12$ (chunk $2 ; M=11.65$ years old), early adolescence for ages 13-16 (chunk 3; $M=14.68$ years old), and late adolescence for ages 17-19 (chunk 4; $M=17.68$ years old). Among these participants, 2,415 provided responses to at least one of the items used to create the dependent variable for Wave 2.

\section{Dependent Variable}

The dependent variable was constructed from Wave 2 self-reported offending items. Violent crime

\footnotetext{
${ }^{1}$ The Longitudinal Cohort Study was based on the stratified sampling design of the Community Survey, however, Sampson (1997; see note 3, p 242) and his associates [Sampson et al., 1997; see note $20, \mathrm{p}$ 924] note that the sample is self-weighting and representative of residences within the neighborhood clusters of Chicago. Therefore, sampling weights were not used in the analyses presented in this study.
} 
TABLE I. Descriptive Statistics for Wave 1 Demographics, Prior Aggression, and DSM-Oriented Scales and Wave 2 Delinquency

\begin{tabular}{|c|c|c|c|c|c|c|c|c|}
\hline \multirow[b]{3}{*}{ Variable } & \multicolumn{2}{|c|}{ Chunk 1} & \multicolumn{2}{|c|}{ Chunk 2} & \multicolumn{2}{|c|}{ Chunk 3} & \multicolumn{2}{|c|}{ Chunk 4} \\
\hline & \multicolumn{2}{|c|}{ Ages 7-9 } & \multicolumn{2}{|c|}{ Ages $10-12$} & \multicolumn{2}{|c|}{ Ages $13-16$} & \multicolumn{2}{|c|}{ Ages 17-19 } \\
\hline & $M$ & $\mathrm{SD}$ & $M$ & SD & $M$ & $\mathrm{SD}$ & $M$ & SD \\
\hline Age & 8.64 & 0.49 & 11.65 & 0.49 & 14.68 & 0.51 & 17.68 & 0.48 \\
\hline Affective (PC) & 1.84 & 2.31 & 1.82 & 2.45 & 2.35 & 2.85 & - & - \\
\hline Anxiety (PC) & 2.12 & 1.86 & 1.82 & 1.85 & 1.98 & 2.06 & - & - \\
\hline Somatic (PC) & 1.02 & 1.68 & 1.26 & 1.75 & 1.54 & 2.04 & - & - \\
\hline ADHP (PC) & 3.00 & 2.50 & 2.60 & 2.36 & 2.70 & 2.45 & - & - \\
\hline ODP (PC) & 2.94 & 2.37 & 2.78 & 2.28 & 3.02 & 2.58 & - & - \\
\hline Affective (Y)/depressive (YA) & - & - & 3.92 & 3.33 & 4.52 & 3.48 & 5.34 & 4.08 \\
\hline Anxiety (Y \& YA) & - & - & 3.38 & 2.20 & 3.60 & 2.17 & 4.54 & 2.26 \\
\hline Somatic (Y \& YA) & - & - & 3.22 & 2.76 & 3.07 & 2.53 & 2.66 & 2.80 \\
\hline $\operatorname{ADHP}(\mathrm{Y})$ & - & - & 3.00 & 2.20 & 3.72 & 2.39 & - & - \\
\hline ODP (Y)/APP (YA) & - & - & 2.70 & 2.06 & 3.91 & 2.40 & 5.52 & 4.14 \\
\hline \multicolumn{9}{|l|}{ Gender } \\
\hline Female & $46.5 \%$ & & $50.7 \%$ & & $52.1 \%$ & & $49.9 \%$ & \\
\hline Male & $53.5 \%$ & & $49.3 \%$ & & $47.9 \%$ & & $50.1 \%$ & \\
\hline \multicolumn{9}{|l|}{ Race $^{*}$} \\
\hline Non-white & $36.5 \%$ & & $40.1 \%$ & & $37.7 \%$ & & $41.9 \%$ & \\
\hline Hispanic & $48.7 \%$ & & $46.0 \%$ & & $46.3 \%$ & & $39.1 \%$ & \\
\hline White & $14.9 \%$ & & $14.0 \%$ & & $16.0 \%$ & & $19.0 \%$ & \\
\hline \multicolumn{9}{|l|}{$S E S^{*}$} \\
\hline Low & $31.2 \%$ & & $30.1 \%$ & & $26.7 \%$ & & $21.5 \%$ & \\
\hline Middle & $38.7 \%$ & & $43.3 \%$ & & $44.6 \%$ & & $67.2 \%$ & \\
\hline High & $30.0 \%$ & & $26.6 \%$ & & $28.7 \%$ & & $11.3 \%$ & \\
\hline Prior violent (ever) ${ }^{*}$ & $17.1 \%$ & & $34.7 \%$ & & $61.2 \%$ & & $55.3 \%$ & \\
\hline Violent crime wave $2^{*}$ & $16.6 \%$ & & $32.6 \%$ & & $39.3 \%$ & & $33.7 \%$ & \\
\hline
\end{tabular}

PC, primary caregiver; Y, youth; YA, young adult; ADHP, attention deficit/hyperactivity problems; ODP, oppositional defiant problems; APP, antisocial personality problems.

${ }^{*}$ Chi-square significant at $P<.05$. Mean comparisons across age chunks were not calculated for the DSM scales owing to informant and instrumentation differences.

was measured as an additive index comprised of seven items pertaining to the youths' self-reported offending behaviors within the past year $(\alpha=.587){ }^{2}$ including: hitting someone you live with $(9.0 \%$ endorsed this item), hitting someone you do not live with ( $18.7 \%$ endorsed this item), attacking someone with a weapon $(2.9 \%$ endorsed this item), throwing objects at people $(8.7 \%$ endorsed this item), shooting at someone (1.2\% endorsed this item), being in a gang fight $(4.0 \%$ endorsed this item), and threatening to hurt someone (5.5\% endorsed this item). Owing to the skewed distribution and low frequencies at younger ages for these data, a dichotomous indicator of whether the youths had reported

\footnotetext{
${ }^{2}$ Although the $\alpha$ coefficients for several of the indicators reported in this study are below .70 threshold typically used to indicate a mediocre level of internal consistency, the summary measures of offending and the DSM-oriented scales have been well established in the criminological and psychological literatures, respectively. Moreover, as expected, the $\alpha$ coefficients for the PHDCN sample increase across age chunks. Because this study examines behavior in young childhood and the final offending measures reflected dichotomous indicators, we included these measures in the analyses.
}

committing any of these violent behaviors was created for analysis. Table I contains descriptive statistics for the violence measure. The prevalence rates for violence ranged from 16.6 to $39.3 \%$ across the four age chunks. Younger youths reported significantly lower prevalence rates for violence than older youths $\left(\chi^{2}[3, N=2,415]=85.93, P<.001\right)$.

\section{Independent and Control Variables}

Sociodemographic characteristics. The sociodemographic variables were created from youthand parent-reported indicators for Wave 1 (see Table I for descriptives). A dichotomous measure for gender was included, with male as the reference category. Gender was evenly divided across the developmental chunks. Race was coded as $0=$ White, $1=$ Hispanic Latina, and $2=$ non-White (mostly Black/AfricanAmerican [89.9\%]; reference category). Slightly less than half the sample was Hispanic, less than $20 \%$ was White, and the remaining youths were non-White, mostly Black. The younger age chunks contained significantly more Hispanic youths than the older 
chunks $\left(\chi^{2}[6, N=2,411]=13.67, P<.05\right)$. Family SES was based on an imputed indicator available in the PHDCN data for maximum SES reported by the primary caregiver or young adult at Wave 1 . The imputed maximum SES measure is based on the Duncan Socio-Economic Index [SEI; Reiss, 1961] of social status which ranges from 0 to 100 , with 100 being "excellent" or highest social stratification level. For youths missing SEI information (11\%), a maximum SES score was imputed by PHDCN researchers based on data collected for maximum parental/young adult education level and salary. Youths missing SEI, education, and salary data were treated as missing in the analyses. For the purposes of analyses, this indicator was recoded based on quartiles such that $0=$ top 25 th percentile or high SES, $1=$ middle 50 th percentile or middle SES, and 2 =bottom 25th percentile or low SES (reference category). Looking across the different age chunks, the proportion of middle SES youths increased with age. The older developmental chunks contained significantly more middle SES youths than the younger chunks $\left(\chi^{2}[6\right.$, $N=2,281]=93.57, P<.001)$.

Prior violence. As earlier engagement in aggressive or violent behaviors has consistently been shown to influence future antisocial behavior, a control variable for prior violence was used in the analyses. An index for ever reported prior violent behavior $(\alpha=.642)$ was created from the same items from Wave 1 as the dependent variable for violence at Wave 2, except Wave 1 did not contain items for shooting at someone or threatening to hurt someone. Owing to skewness and low frequencies, this indicator was also dichotomized $(0=$ never; $1=$ ever). As shown in Table I, the prevalence rates for prior violence ranged from 17.1 to $61.2 \%$ across the four age chunks. Younger youths reported significantly lower prevalence rates for prior violence than older youths $\left(\chi^{2}[3, N=2,389]=304.89\right.$, $P<.001)$.

DSM-oriented scales. At Wave 1, primary caregivers completed the 120-item Child Behavior Checklist [CBCL; Achenbach, 1991a, 1992] for chunks 1, 2, and 3. Primary caregivers were asked to report whether the assessment items applied to their child's behavior within the past 6 months. Youths were also asked to self-report the same problem behaviors as measured in the CBCL. For chunks 2 and 3, youths were administered the Youth Self-Report [YSR; Achenbach, 1991b], a 112-item instrument containing comparable items to the CBCL and appropriate for older children. For chunk 4, older youths were administered the Young Adult Self-Report [YASR; Achenbach,
1997] instrument, a 138-item instrument containing comparable items to the CBCL and appropriate for adults aged 18-30. Responses were $0=$ not true, $1=$ somewhat true, and $2=$ very true. For each of the DSM-oriented scales, youths missing greater than $30 \%$ of the original Achenbach items were excluded; thereafter, missing values were conservatively assumed to be zero. Achenbach and Rescorla [2001, 2003] provide raw score conversions to $T$ scores to allow for comparisons with normalized populations. ${ }^{3}$ As stated earlier, the CBCL, YSR, and YASR are widely recognized as reliable and valid instruments that include age and gender appropriate measures of emotional and behavioral problems among children and young adults [Achenbach and Edelbrock, 1983; Achenbach and Rescorla, 2001; Achenbach et al., 2003]. Table I presents the descriptive statistics for the DSMoriented scales.

Achenbach and his co-workers have developed several DSM-oriented scales from the CBCL, YSR, and YASR for mental health problems in childhood and adolescence, of which five of six scales are included here: Affective Problems, Anxiety Problems, Somatic Problems, ADHP, and ODP. Additive indexes for Affective Problems were created from the CBCL $(\alpha=.692)$ for chunks 1,2 , and 3 and the YSR $(\alpha=.714)$ for chunks 2 and 3 , and comparable Depressive Problems for chunk 4 from the YASR $(\alpha=.792)$. The Affective/Depressive Problems indexes are summary measures of the raw scores for twelve items, including frequent crying, attempts to harm one's self or suicide, sleeping problems, and feelings of worthlessness. Additive indexes for DSM-oriented Anxiety Problems were created from raw scores for six items from the CBCL $(\alpha=.543)$ for chunks 1,2 , and 3 and the YSR $(\alpha=.564)$ for chunks 2 and 3, and five items from the YASR $(\alpha=.606)$ for chunk 4 . These measures include problems, such as unusual dependence on adults, fear of certain situations, nervousness, and worrying. Additive indexes for Somatic Problems were created from seven items from the CBCL $(\alpha=.687)$ for chunks 1,2 , and 3 and the YSR $(\alpha=.721)$ for chunks 2 and 3 , and eight items from the YASR $(\alpha=.756)$ for chunk 4 . These items describe physical problems with unknown medical causes, such as headaches, nausea, rashes, and

\footnotetext{
${ }^{3}$ Because the $T$ scores range from 50 to 100 , Achenbach and Rescorla [2001] recommend using raw scores for analyses to avoid problems associated with using censored measures. Therefore, raw scores were used in the analyses reported in this article and converted to $T$ scores for interpretation.
} 
vomiting. Additive indexes for five items related to $A D H P$ were created from the CBCL $(\alpha=.691)$ for chunks 1, 2, and 3 and the YSR $(\alpha=.663)$ for chunks 2 and 3. Among the older adolescents in chunk 4 (ages 17-19), less than $50 \%$ of the items used to create Achenbach's ADHP scale were available for the PHDCN; therefore, an ADHP scale was not created for chunk 4. Problems, such as restlessness, lack of concentration, impulsivity, and loudness, were included in the ADHP scales.

Last, DSM-oriented scales for $O D P$ were created from the CBCL $(\alpha=.822)$ for chunks 1,2 , and 3 and the YSR $(\alpha=.787)$ for chunks 2 and 3, and comparable Antisocial Personality Problems (APP) from the YASR $(\alpha=.780)$ for chunk 4 . The ODP index is a summary measure of the raw scores for five items, with problems, such as arguing and disobeying parents/teachers and having a hot temper. The APP index contained items similar to ODP and Conduct Problems in youths. The APP index is a summary measure of the raw scores for 15 items, such as arguing a lot, being mean to others, lack of guilt, lying, threatening people, fighting, and having a bad temper. This DSM-oriented scale was included here to allow for a continual examination of developmentally appropriate problem behaviors across the age chunks, because ODP is one of the disruptive disorders that may be diagnosed during childhood and adolescence, and perspectives within developmental psychology have argued that it is part of a continuum as a diagnostic precursor to $\mathrm{CD}$, and then APP later in life [see e.g., American Psychiatric Association, 2000; Loeber et al., 2002].

As stated earlier, to avoid tautological issues the construct for Conduct Problems was excluded from this analysis because these measures involve property or violent crime with few exceptions, whereas the DSM-oriented scales for ODP and APP included a sizeable number of noncriminal norm-violating behaviors within their respective scales to address potential multicollinearity and tautology concerns. Empirical investigations of the developmental sequencing of disruptive behaviors have suggested somewhat different estimates of continuity and stability over the lifecourse depending on the temporal framework employed, with retrospective studies of antisocial adults reporting that a majority of these persons had significant childhood Oppositional and Conduct Problems. Conversely, many prospective studies indicate that less than half the children with Conduct Problems will progress to Antisocial Personality Disorder in adulthood [Robins, 1966; Zoccolillo et al., 1992], thereby suggesting considerable heterogeneity and subgroups in disruptive youngsters [Frick, 1998]. Although some researchers have posited a more direct relationship between $C D$ and adult antisocial behaviors when compared with ODP, other scholars have found evidence of an independent link between ODP as an antecedent of poor adult outcomes [see August et al., 1999; Langbehn et al., 1998]. For studies focusing on the etiology of violence, recent evidence shows that children who display early Oppositional Problems, who then progress to more serious types of Conduct Problems, typically do not stop acting on these less serious oppositional behaviors; instead, these youngsters add to the variety of disruptive and aggressive behaviors that they exhibit as they get older [Frick, 1998; Lahey et al., 1995]. As such, the present inquiry into whether ODP and then Antisocial Personality Problems may influence offending behaviors at various stages of childhood and adolescence will be a valuable contribution to the body of developmental and life-course criminology. Models were analyzed using both the original 15-item APP scale and an adjusted APP scale, which omitted six items that reflected serious deviant behavior, because they presented tautological issues when considering youth violence outcomes (i.e., damaging property, fighting, attacking people, stealing, doing things to get into trouble with the law, and threatening to hurt people). In general and as expected, the youths self-reported similar or higher levels of problems as their primary caregivers reported, with such problems showing stable or slightly increasing trends over the developmental stages.

\section{Analysis Strategy}

Logistic regression analyses were used to examine the relationship between DSM-oriented scales at Wave 1 and violent crime prevalence at Wave 2, but controlling for a number of demographic characteristics from Wave 1 (significance level of $P<.05$ ). As earlier discussed, one goal of this study was to examine the effects of mental health problems on future violence within developing stages; therefore, regression analyses were performed separately for four developmental age groups (chunk $1=$ ages 7-9; chunk $2=$ ages 10-12; chunk $3=$ ages 13-16; chunk $4=$ ages 17-19). For chunk 1, the PHDCN contains data for the CBCL, administered to primary caregivers about their children. Six regression models (one for each DSM-oriented scale and one for comorbidity) were estimated for chunk 1 . Because multiple tests were conducted simultaneously on violence within the chunk 1 subsample, 
a Bonferroni $P<.0083(.05 / 6)$ was used as the significance level to correct for Type I error. For chunks 2 and 3, there are two informant sources because the PHDCN administered the CBCL to primary caretakers and the YSR to the youths. Twelve regression models (one for each DSMoriented scale and one for comorbidity for parent and youth reports) were estimated for chunk 2 and chunk 3, respectively. For chunks 2 and 3, a Bonferroni $P<.0042(.05 / 12)$ was used as the significance level. For chunk 4, the PHDCN only contains self-reported youth data from the YASR, but the ADHD DSM-oriented scale is missing from the PHDCN data for this chunk. Therefore, only five models (one for the four DSM-oriented scales and one for comorbidity) were estimated for chunk 4. For chunk 4, a Bonferroni $P<.01(.05 / 5)$ was used as the significance level. Overall, 35 models were estimated for this study.

\section{RESULTS}

\section{Bivariate Analyses}

An examination of bivariate correlations between the measures indicated that a few variables demonstrated moderately strong correlations. The correlations between the DSM-oriented scales at Wave 1 and selfreported violence at Wave 2 are reported in Tables II and III by age chunks. For chunks 1-3, ADHP was strongly associated with ODP and Affective Problems was moderately to strongly associated with Anxiety Problems. For chunk 4, Depression was strongly correlated with Anxiety, Somatic, and APP. These moderately strong correlations between ADHP and
ODP and Affective/Depressive Problems and Anxiety Problems were consistent with the literature [Barkley, 1998; Loeber et al., 2000; Mrug et al., 2008; Wittchen et al., 2000]; however, variance inflation factor scores for the subsequent regression analyses were well below four, indicating that multicollinearity was not a problem [Fox, 1991] in subsequent regression analyses. Overall, the DSM-oriented scales were positively associated with future violence prevalence.

Furthermore, as shown in Table I, comparisons across chunks indicated that older age chunks contained significantly more youth who engaged in earlier $\left(\chi^{2}[3, N=2,389]=304.89, P<.001\right)$ and future violence $\left(\chi^{2}[3, N=2,415]=85.93, P<.001\right)$. There were no gender differences across the chunks, however, there were significantly more White $\left(\chi^{2}[6, N=2,411]=13.67, P=.034\right)$ and middle SES $\left(\chi^{2}[6, N=2,281]=93.57, P<.001\right)$ youth in older

TABLE II. Correlations for DSM-Oriented Scales at Wave 1 and Violence at Wave 2 for Chunks 1 and 4 (Chunk 1 Below Diagonal. Chunk 4 Above Diagonal)

\begin{tabular}{|c|c|c|c|c|c|c|}
\hline & 1. & 2. & 3. & 4. & 5. & 6. \\
\hline 1. Affec & 1.00 & $0.58^{*}$ & $0.53^{*}$ & - & 0.01 & 0.08 \\
\hline 2. Anxiety & $0.50^{*}$ & 1.00 & $0.39^{*}$ & - & $0.35^{*}$ & 0.04 \\
\hline 3. Somatic & $0.40^{*}$ & $0.28^{*}$ & 1.00 & - & $0.35^{*}$ & -0.02 \\
\hline 4. ADHP & $0.45^{*}$ & $0.42^{*}$ & $0.24^{*}$ & 1.00 & - & - \\
\hline 5. $\mathrm{ODP} / \mathrm{A}$ & $0.46^{*}$ & $0.37^{*}$ & $0.28 *$ & $0.65^{*}$ & 1.00 & $0.28^{*}$ \\
\hline 6. Violence & $0.09^{*}$ & $0.09^{*}$ & $0.12^{*}$ & $0.11^{*}$ & $0.19^{*}$ & 1.00 \\
\hline
\end{tabular}

For chunk 1, DSM-oriented scales are based on primary caregiver reports for the child behavior checklist. For chunk 4, DSM-oriented scales are based on youth self-reports for the young adult self-report. ADHP, attention deficit/hyperactivity problems. ADHP not available for youths in chunk 4; ODP, oppositional defiant problems; APP, antisocial personality problems.

${ }^{*} P<.05$.

TABLE III. Correlations for DSM-Oriented Scales at Wave 1 and Violence at Wave 2 for Chunks 2 and 3 (Chunk 2 Below Diagonal. Chunk 3 Above Diagonal)

\begin{tabular}{|c|c|c|c|c|c|c|c|c|c|c|c|c|}
\hline & & 1. & 2. & 3. & 4. & 5. & 6. & 7. & 8. & 9. & 10. & 11. \\
\hline 1. & Affective (PC) & 1.00 & $0.59^{*}$ & $0.42^{*}$ & $0.46^{*}$ & $0.51^{*}$ & $0.20^{*}$ & $0.15^{*}$ & $0.11^{*}$ & $0.10^{*}$ & $0.18^{*}$ & $0.09^{*}$ \\
\hline 2. & Anxiety (PC) & $0.49^{*}$ & 1.00 & $0.31^{*}$ & $0.48^{*}$ & $0.42^{*}$ & $0.09^{*}$ & $0.21^{*}$ & 0.08 & 0.08 & $0.14^{*}$ & $0.09^{*}$ \\
\hline 3. & Somatic (PC) & $0.43^{*}$ & $0.35^{*}$ & 1.00 & $0.25^{*}$ & $0.28^{*}$ & $0.16^{*}$ & $0.09^{*}$ & $0.23^{*}$ & 0.07 & $0.13^{*}$ & 0.06 \\
\hline 4. & $\mathrm{ADHP}(\mathrm{PC})$ & $0.45^{*}$ & $0.38^{*}$ & $0.22^{*}$ & 1.00 & $0.63^{*}$ & 0.07 & $0.10^{*}$ & $0.10^{*}$ & $0.23^{*}$ & $0.25^{*}$ & $0.15^{*}$ \\
\hline 5. & ODP (PC) & $0.47^{*}$ & $0.36^{*}$ & $0.25^{*}$ & $0.59^{*}$ & 1.00 & $0.09^{*}$ & 0.04 & $0.09^{*}$ & $0.19^{*}$ & $0.39^{*}$ & $0.18^{*}$ \\
\hline 6. & Affective (Y) & $0.27^{*}$ & $0.21^{*}$ & $0.08^{*}$ & $0.21^{*}$ & $0.23^{*}$ & 1.00 & $0.55^{*}$ & $0.46^{*}$ & $0.51^{*}$ & $0.46^{*}$ & -0.01 \\
\hline 7. & Anxiety (Y) & $0.15^{*}$ & $0.19^{*}$ & 0.04 & $0.09^{*}$ & 0.03 & $0.59^{*}$ & 1.00 & $0.31^{*}$ & $0.42 *$ & $0.37^{*}$ & 0.01 \\
\hline 8. & Somatic (Y) & $0.11^{*}$ & $0.16^{*}$ & $0.19^{*}$ & $0.17^{*}$ & $0.10^{*}$ & $0.46^{*}$ & $0.35^{*}$ & 1.00 & $0.35^{*}$ & $0.28^{*}$ & 0.00 \\
\hline 9. & $\operatorname{ADHP}(\mathrm{Y})$ & $0.14^{*}$ & $0.12^{*}$ & -0.01 & $0.26^{*}$ & $0.23^{*}$ & $0.55^{*}$ & $0.41^{*}$ & $0.31^{*}$ & 1.00 & $0.59^{*}$ & 0.05 \\
\hline 10. & ODP (Y) & $0.11^{*}$ & $0.14^{*}$ & 0.07 & $0.20^{*}$ & $0.27^{*}$ & $0.45^{*}$ & $0.31^{*}$ & $0.28^{*}$ & $0.58 *$ & 1.00 & $0.20^{*}$ \\
\hline 11. & Violent & 0.04 & 0.02 & 0.08 & $0.11^{*}$ & $0.13^{*}$ & $0.08^{*}$ & 0.01 & $0.11^{*}$ & $0.18^{*}$ & $0.24^{*}$ & 1.00 \\
\hline
\end{tabular}

PC, Primary caregiver reports for DSM-oriented scales from child behavior checklist; Y, youth self-reports for DSM-oriented scales from youth self-report; ADHP, attention deficit/hyperactivity problems; ODP, oppositional defiant problems.

${ }^{*} P<.05$. 
age chunks. Mean comparisons across chunks for the DSM-oriented scales were not conducted owing to scale and informant source differences across age.

\section{Logistic Regression Analyses}

Table IV reports the logistic regression results for violent offending regressed on the demographic variables, prior violence, and parent-reported DSM-oriented scales, separately and combined, for chunk 1 (ages 7-9). The models looking at the DSMoriented scales separately accounted for $19-22 \%$ of the variance in violence. The racial and prior violence effects were the strongest predictors of future violence among the youths in chunk 1 . Among this youngest group in the sample, primary caregiver reported of high scores on the DSMoriented scales for affective problems $(b=.14)$, anxiety problems $(b=.19)$, and ODP $(b=.20)$ significantly increased the odds of future violent crime, when examining the effects of these scales separately and controlling for all else. Using an adjusted $P$-value, somatic and ADHP problems were not separately significantly associated with future violence.

In Model 6 of Table IV, comorbidity among the DSM-oriented scales in predicting future violent prevalence was examined. The comorbidity model accounted for $23 \%$ of the variance, slightly more than the individual DSM predictor models. The effects of affective and anxiety problems were reduced to nonsignificance in the comorbidity model. The DSM-oriented scale for ODP was the only significant mental health predictor of future violence when controlling for the other four DSMoriented constructs. This finding suggests that either the variation in affective and anxiety problems was shared with other mental health problems, or the effects of affective or anxiety problems among PHDCN youths in middle childhood were spurious.

For logistic regression, the odds ratio serves as an indication of effect size. Taking other mental health problems and earlier aggression into account, a oneunit increase in parent reports of ODP increased the odds of future violent behavior by $20.2 \%$ (EXP[.184]). The implications of this statement are especially important when one considers the fact that this study employed Achenbach and Rescorla's [2001, 2003] DSM-oriented scale for ODP, which ranges from 0 to 10 and captures normal-, borderline-, and clinical-level problems, rather than a categorical indicator of ODP. Moreover, the logistic regression results can be used to calculate the probability of a youth endorsing future violence for normal, borderline, and clinical ranges of ODP. For a white, middle class male with no history of

TABLE IV. Logistic Regression Models for the Effects of Primary Caregivers' Reports of DSM-Oriented Problems at Wave 1 on Youths' Self-Reported Violent Crime at Wave 2 for Chunk 1 (Ages 7-9)

\begin{tabular}{|c|c|c|c|c|c|c|c|c|c|c|c|c|}
\hline & \multicolumn{2}{|c|}{ Model 1} & \multicolumn{2}{|c|}{ Model 2} & \multicolumn{2}{|c|}{ Model 3} & \multicolumn{2}{|c|}{ Model 4} & \multicolumn{2}{|c|}{ Model 5} & \multicolumn{2}{|c|}{ Model 6} \\
\hline & $b$ & $\operatorname{SE}(b)$ & $b$ & $\operatorname{SE}(b)$ & $b$ & $\operatorname{SE}(b)$ & $B$ & $\operatorname{SE}(b)$ & $b$ & $\operatorname{SE}(b)$ & $b$ & $\operatorname{SE}(b)$ \\
\hline \multicolumn{13}{|l|}{ Gender } \\
\hline Female & -0.53 & 0.24 & -0.56 & 0.24 & -0.52 & 0.24 & -0.49 & 0.24 & -0.45 & 0.24 & -0.48 & 0.24 \\
\hline \multicolumn{13}{|l|}{ Race } \\
\hline White & -0.61 & 0.33 & -0.57 & 0.33 & -0.55 & 0.33 & -0.47 & 0.33 & -0.53 & 0.33 & -0.51 & 0.34 \\
\hline Hispanic & $-1.36^{*}$ & 0.27 & $-1.35^{*}$ & 0.27 & $-1.22^{*}$ & 0.26 & $-1.27^{*}$ & 0.26 & $-1.27^{*}$ & 0.27 & $-1.30^{*}$ & 0.27 \\
\hline SES & -0.31 & 0.31 & -0.30 & 0.31 & -0.30 & 0.31 & -0.30 & 0.31 & -0.22 & 0.31 & -0.24 & 0.32 \\
\hline \multicolumn{13}{|l|}{ High } \\
\hline Middle & -0.14 & 0.28 & -0.13 & 0.28 & -0.05 & 0.28 & -0.14 & 0.28 & -0.17 & .29 & -0.13 & 0.29 \\
\hline No prior violence & $-1.33^{*}$ & 0.25 & $-1.32^{*}$ & 0.25 & $-1.36^{*}$ & 0.25 & $-1.35^{*}$ & 0.25 & $-1.30^{*}$ & .25 & $-1.32^{*}$ & 0.25 \\
\hline \multicolumn{13}{|l|}{$D S M$-scales } \\
\hline Affective & $0.14^{*}$ & 0.05 & & & & & & & & & 0.01 & 0.06 \\
\hline Anxiety & & & $0.19^{*}$ & 0.06 & & & & & & & 0.10 & 0.07 \\
\hline Somatic & & & & & 0.14 & 0.06 & & & & & 0.06 & 0.07 \\
\hline ADHP & & & & & & & 0.11 & 0.04 & & & -0.05 & 0.06 \\
\hline ODP & & & & & & & & & $0.20^{*}$ & .05 & $0.18^{*}$ & 0.06 \\
\hline Intercept & 0.12 & & -0.06 & & 0.16 & & -0.02 & & -0.40 & & -0.46 & \\
\hline-2 Log likelihood & 513.21 & & 511.18 & & 514.01 & & 514.63 & & 503.22 & & 496.94 & \\
\hline Model $\chi^{2} / \mathrm{df}$ & $81.17 / 7^{*}$ & & $83.19 / 7^{*}$ & & $80.00 / 7^{*}$ & & $79.38 / 7^{*}$ & & $91.16 / 7^{*}$ & & $96.71 / 11^{*}$ & \\
\hline Pseudo- $R^{2}$ controls only & 0.18 & & 0.18 & & 0.18 & & 0.18 & & 0.18 & & 0.18 & \\
\hline Pseudo- $R^{2}$ full model & 0.20 & & 0.20 & & 0.19 & & 0.19 & & 0.22 & & .23 & \\
\hline$n$ & 659 & & 659 & & 658 & & 658 & & 659 & & 657 & \\
\hline
\end{tabular}

ADHP, Attention deficit/hyperactivity problems; ODP, Oppositional defiant problems.

*Bonferroni $(\alpha=.05) P<.0083$. 
violence, the predicted probability of future violent behavior ranged from 9.1 to $20.2 \%$ in the normal threshold, $23.3 \%$ in the borderline threshold, and from 26.7 to $38.8 \%$ in the clinical threshold of ODP. For a white, middle class male with prior violence, the predicted probability of future violent behavior ranged from 27.4 to $48.6 \%$ in the normal threshold, $53.2 \%$ in the borderline threshold, and from 57.7 to $70.3 \%$ in the clinical threshold of ODP. The predicted probabilities show the practical utility for clinicians in looking across these distinctions, as borderline cases have almost as great a likelihood of committing future violence as the low clinical group; such results make a strong argument for identifying subclinical levels of oppositional youth in addition to clinically ODP youngsters for interventions.

Using an adjusted $P$-value, it is interesting that none of the models (Models 7 through 18) examining the effects of primary caregiver-based DSMoriented problems in chunks $2(10-12$ year olds) and 3 (13-16 year olds) produced significant associations between mental health problems and future violent behavior. In the spirit of brevity, tables reporting these null findings have been omitted from the results section presented here. (These tables are available upon request from the corresponding author.)
Table $\mathrm{V}$ is the first of three tables that reports the logistic regression findings for the youths' self-reported DSM-oriented scales. Compared with the primary caregiver models for chunk 2, the self-report-based DSM models explained approximately the same proportion of the variance in violence for the affective-only, anxiety-only, and somatic-only models (13.4, 13.2, and $13.6 \%$, respectively) but slightly more of the variance for the ADHP-only $(14.9 \%$; a $6 \%$ increase) and ODP-only (16.8\%; an 18\% increase) models. For chunk 2, prior violence was the strongest predictor of future violence in all models. That is, youths with affective, anxiety, or somatic problems were no more likely to engage in future violence than those without such mental health problems. On the other hand, youths who reported higher levels of difficulties associated with ADHP $(b=.13)$ or ODP $(b=.20)$ were significantly more likely to report future violent behavior at Wave 2. Each one-unit increase in ADHP increased the odds of reporting violence by $14 \%$ (EXP[.131]), and each one-unit increase in ODP increased the odds of violence by $22.4 \%$ (EXP[.202]).

When examining comorbidity of all DSM-oriented problems among the youths in chunk 2 based on self-reported indicators, only $\operatorname{ODP}(b=.19)$ remained as a significant predictor of violence. Hence, the comorbidity model (Model 24) suggested

TABLE V. Logistic Regression Models for the Effects of Youths' Self-reports of DSM-Oriented Problems at Wave 1 on SelfReported Violent Crime at Wave 2 for Chunk 2 (Ages 10-12)

\begin{tabular}{|c|c|c|c|c|c|c|c|c|c|c|c|c|}
\hline & \multicolumn{2}{|c|}{ Model 19} & \multicolumn{2}{|c|}{ Model 20} & \multicolumn{2}{|c|}{ Model 21} & \multicolumn{2}{|c|}{ Model 22} & \multicolumn{2}{|c|}{ Model 23} & \multicolumn{2}{|c|}{ Model 24} \\
\hline & $b$ & $\mathrm{SE}(b)$ & $b$ & $\mathrm{SE}(b)$ & $b$ & $\mathrm{SE}(b)$ & $b$ & $\mathrm{SE}(b)$ & $b$ & $\mathrm{SE}(b)$ & $b$ & $\operatorname{SE}(b)$ \\
\hline \multicolumn{13}{|l|}{ Gender } \\
\hline Female & -0.43 & 0.18 & -0.41 & 0.18 & -0.42 & 0.18 & -0.44 & 0.18 & -.49 & .18 & -0.46 & .18 \\
\hline \multicolumn{13}{|l|}{ Race } \\
\hline White & -0.61 & 0.28 & -0.61 & 0.28 & -0.60 & 0.28 & -0.59 & 0.29 & -0.64 & 0.29 & -0.59 & 0.29 \\
\hline Hispanic & -0.45 & 0.20 & -0.42 & 0.20 & -0.40 & 0.20 & -0.46 & 0.20 & -0.53 & 0.20 & -0.47 & 0.21 \\
\hline \multicolumn{13}{|l|}{ SES } \\
\hline High & 0.03 & 0.25 & 0.02 & 0.25 & 0.02 & 0.25 & -0.03 & 0.25 & -0.07 & 0.25 & -0.12 & 0.25 \\
\hline Middle & 0.16 & 0.21 & 0.14 & 0.21 & 0.16 & 0.21 & 0.14 & 0.21 & 0.12 & 0.30 & 0.08 & 0.22 \\
\hline No prior violence & $-1.09^{*}$ & 0.19 & $-1.13^{*}$ & 0.18 & $-1.09^{*}$ & 0.18 & $-0.97^{*}$ & 0.19 & $-0.81^{*}$ & 0.20 & $-0.78^{*}$ & 0.20 \\
\hline \multicolumn{13}{|l|}{ DSM-scales } \\
\hline Affective & 0.03 & .03 & & & & & & & & & -0.03 & 0.04 \\
\hline Anxiety & & & -0.00 & 0.04 & & & & & & & -0.08 & 0.05 \\
\hline Somatic & & & & & 0.05 & .03 & & & & & 0.03 & 0.04 \\
\hline ADHP & & & & & & & $0.13^{*}$ & 0.04 & & & 0.09 & 0.05 \\
\hline ODP & & & & & & & & & $0.20^{*}$ & 0.05 & $0.19^{*}$ & 0.06 \\
\hline Intercept & 0.22 & & 0.36 & & 0.17 & & -0.10 & & -0.30 & & -0.30 & \\
\hline-2 Log likelihood & 768.42 & & 769.61 & & 767.63 & & 757.78 & & 750.27 & & 742.57 & \\
\hline Model $\chi^{2} / \mathrm{df}$ & $67.03 / 7^{*}$ & & $65.85 / 7^{*}$ & & $67.82 / 7^{*}$ & & $74.53 / 7^{*}$ & & $85.19 / 7^{*}$ & & $89.73 / 11^{*}$ & \\
\hline Pseudo- $R^{2}$ controls only & 0.13 & & 0.13 & & 0.13 & & 0.13 & & 0.13 & & 0.13 & \\
\hline Pseudo- $R^{2}$ full model & 0.13 & & 0.13 & & 0.14 & & 0.15 & & 0.17 & & 0.18 & \\
\hline$n$ & 663 & & 663 & & 663 & & 659 & & 663 & & 659 & \\
\hline
\end{tabular}

ADHP, Attention deficit/hyperactivity problems; ODP, Oppositional defiant problems.

*Bonferroni $(\alpha=.05) P<.0042$. 
that other measures in the model shared the variation in ADHP, to the point of nonsignificance. For each one-unit increase in self-reported ODP problems, the odds of youths self-reporting future violence increased $21.1 \%$ (EXP[.191]), controlling for all else. For a white, middle class male with no history of violence in chunk 2, the predicted probability of future violent behavior ranged from 16.9 to $34.5 \%$ in the normal threshold, $38.9 \%$ in the borderline threshold, and from 43.6 to $57.8 \%$ in the clinical threshold of ODP. For a white, middle class male with prior violence, the predicted probability of future violent behavior ranged from 30.6 to $53.3 \%$ in the normal threshold, $58.1 \%$ in the borderline threshold, and from 62.6 to $74.8 \%$ in the clinical threshold of ODP. Again, the practical use of the normal, borderline, and clinical distinctions across the DSM-oriented problem behaviors becomes even clearer when looking at the similar predicted probabilities of future violence between youth scoring in the borderline and low clinical levels of Oppositional Defiant Problems.

Table VI reports the regression results for youths in chunk 3 (ages 13-16) based on youths' selfreports. In congruence with caretaker models for this age chunk, the youth self-report models explained between 24.2 and $26.8 \%$ of the variance in violent behavior. Similar to primary caregiver reports for the 10-12 year old group, none of the mental health problems significantly predicted violence when examined separately. In the comorbid model, however, the self-report-based Oppositional Defiant Problem scale was a significant predictor of violent crime at Wave $2(b=.17)$. This finding suggests a suppression effect that may be owing, in part, to the negative effects of the other measures in the model.

For each one-unit increase in self-reported ODP problems in chunk 3, the odds of youths selfreporting future violence increased $18.6 \%$ (EXP[.171]), but controlling for all else. For the sake of interpretation, predicted probabilities were calculated again for this subsample of youth. Consequently, for a white, middle class male with no history of violence in chunk 3 , the predicted probability of future violent behavior ranged from 11.5 to $23.5 \%$ in the normal threshold, $26.7 \%$ in the borderline threshold, and from 30.1 to $41.9 \%$ in the clinical threshold of ODP. For a white, middle class male with prior violence, the predicted probability of future violent behavior ranged from 37.8 to $58.8 \%$ in the normal threshold, $62.9 \%$ in the borderline threshold, and from 66.8 to $77.0 \%$ in the clinical threshold of ODP.

TABLE VI. Logistic Regression Models for the Effects of Youths' Self-reports of DSM-Oriented Problems at WAVE 1 on SelfReported Violent Crime at Wave 2 for Chunk 3 (Ages 13-16)

\begin{tabular}{|c|c|c|c|c|c|c|c|c|c|c|c|c|}
\hline & \multicolumn{2}{|c|}{ Model 25} & \multicolumn{2}{|c|}{ Model 26} & \multicolumn{2}{|c|}{ Model 27} & \multicolumn{2}{|c|}{ Model 28} & \multicolumn{2}{|c|}{ Model 29} & \multicolumn{2}{|c|}{ Model 30} \\
\hline & $b$ & $\mathrm{SE}(b)$ & $b$ & $\mathrm{SE}(b)$ & $b$ & $\operatorname{SE}(b)$ & $b$ & $S E(b)$ & $b$ & $\mathrm{SE}(b)$ & $b$ & $\operatorname{SE}(b)$ \\
\hline \multicolumn{13}{|l|}{ Gender } \\
\hline Female & -0.58 & 0.21 & $-0.57^{*}$ & 0.20 & -0.52 & 0.20 & $-0.61^{*}$ & 0.20 & $-0.72^{*}$ & 0.21 & $-0.64^{*}$ & 0.22 \\
\hline \multicolumn{13}{|l|}{ Race } \\
\hline White & -0.60 & 0.29 & -0.60 & 0.29 & -0.61 & 0.29 & -0.61 & 0.30 & -0.68 & 0.30 & -0.67 & 0.31 \\
\hline Hispanic & $-0.80^{*}$ & 0.22 & $-0.79^{*}$ & 0.22 & $-0.79^{*}$ & 0.22 & $-0.79^{*}$ & 0.22 & $-0.88^{*}$ & 0.22 & $-0.84^{*}$ & 0.23 \\
\hline \multicolumn{13}{|l|}{$S E S$} \\
\hline High & -0.18 & 0.28 & -0.18 & 0.28 & -0.18 & 0.28 & -0.19 & 0.28 & -0.19 & 0.28 & -0.17 & 0.29 \\
\hline Middle & -0.14 & 0.25 & -0.14 & 0.25 & -0.13 & 0.25 & -0.16 & 0.25 & -0.10 & 0.26 & -0.11 & 0.26 \\
\hline No prior violence & $-1.71^{*}$ & 0.23 & $-1.71^{*}$ & 0.23 & $-1.75^{*}$ & 0.23 & $-1.71^{*}$ & 0.23 & $-1.46^{*}$ & 0.24 & $-1.54^{*}$ & 0.25 \\
\hline \multicolumn{13}{|l|}{ DSM-scales } \\
\hline Affective & 0.01 & 0.03 & & & & & & & & & -0.01 & 0.04 \\
\hline Anxiety & & & 0.00 & 0.05 & & & & & & & -0.02 & 0.06 \\
\hline Somatic & & & & & -0.04 & 0.04 & & & & & -0.05 & 0.05 \\
\hline ADHP & & & & & & & 0.03 & 0.04 & & & -0.03 & 0.06 \\
\hline ODP & & & & & & & & & 0.13 & .05 & $0.17^{*}$ & 0.06 \\
\hline Intercept & $0.97^{*}$ & & $0.99^{*}$ & & $1.09^{*}$ & & $0.91^{*}$ & & 0.49 & & 0.65 & \\
\hline-2 Log likelihood & 621.36 & & 621.38 & & 620.61 & & 617.65 & & 613.18 & & 606.76 & \\
\hline Model $\chi^{2} / \mathrm{df}$ & $106.86 / 7^{*}$ & & $106.83 / 7^{*}$ & & $107.61 / 7^{*}$ & & $108.70 / 7^{*}$ & & $115.04 / 7^{*}$ & & $119.60 / 11^{*}$ & \\
\hline Pseudo- $R^{2}$ controls only & 0.24 & & 0.24 & & 0.24 & & 0.25 & & 0.24 & & 0.25 & \\
\hline Pseudo- $R^{2}$ full model & 0.24 & & 0.24 & & 0.24 & & 0.25 & & 0.26 & & 0.27 & \\
\hline$N$ & 543 & & 543 & & 543 & & 542 & & 543 & & 542 & \\
\hline
\end{tabular}

ADHP, Attention deficit/hyperactivity problems; ODP, Oppositional defiant problems.

*Bonferroni $(\alpha=.05) P<.0042$. 
TABLE VII. Logistic Regression Models for the Effects of Youths' Self-Reports of DSM-Oriented Problems at Wave 1 on SelfReported Violent Crime at Wave 2 for Chunk 4 (Ages 17-19)

\begin{tabular}{|c|c|c|c|c|c|c|c|c|c|c|}
\hline & \multicolumn{2}{|c|}{ Model 31} & \multicolumn{2}{|c|}{ Model 32} & \multicolumn{2}{|c|}{ Model 33} & \multicolumn{2}{|c|}{ Model 34} & \multicolumn{2}{|c|}{ Model 35} \\
\hline & $b$ & $\operatorname{SE}(b)$ & $b$ & $\operatorname{SE}(b)$ & $B$ & $\mathrm{SE}(b)$ & $b$ & $\mathrm{SE}(b)$ & $b$ & $\operatorname{SE}(b)$ \\
\hline \multicolumn{11}{|l|}{ Gender } \\
\hline Female & $-1.13^{*}$ & 0.28 & $-0.93^{*}$ & 0.27 & $-.98^{*}$ & .28 & $-.90^{*}$ & .27 & $-.96^{*}$ & .30 \\
\hline \multicolumn{11}{|l|}{ Race } \\
\hline White & $-0.98 *$ & 0.37 & $-0.93^{*}$ & 0.36 & -.88 & .36 & -.90 & .37 & -.94 & .38 \\
\hline Hispanic & -0.15 & 0.28 & -0.12 & 0.28 & -.07 & .28 & -.15 & .28 & -.15 & .29 \\
\hline \multicolumn{11}{|l|}{ SES } \\
\hline High & 0.77 & 0.46 & 0.68 & 0.46 & .70 & .45 & .61 & .46 & .66 & .47 \\
\hline Middle & 0.61 & 0.33 & 0.62 & 0.33 & .64 & .33 & .50 & .33 & .48 & .34 \\
\hline No prior violence & $-1.58^{*}$ & 0.29 & $-1.65^{*}$ & 0.28 & $-1.62^{*}$ & .28 & $-1.38^{*}$ & .30 & $-1.37^{*}$ & .30 \\
\hline \multicolumn{11}{|l|}{ DSM-scales } \\
\hline Depressive & $0.09^{*}$ & .03 & & & & & & & .07 & .05 \\
\hline Anxiety & & & 0.07 & 0.06 & & & & & -.05 & .07 \\
\hline Somatic & & & & & .06 & .05 & & & -.03 & .05 \\
\hline $\mathrm{APP}$ & & & & & & & $.13^{*}$ & .03 & $.12^{*}$ & .04 \\
\hline Intercept & -0.44 & & -0.30 & & -.20 & & -.76 & & -.74 & \\
\hline-2 Log likelihood & 394.48 & & 401.65 & & 400.45 & & 387.24 & & 383.29 & \\
\hline Model $\chi^{2} / \mathrm{df}$ & $83.24 / 7^{*}$ & $76.07 / 7^{*}$ & $75.02 / 7^{*}$ & $90.49 / 7^{*}$ & $92.18 / 10^{*}$ & & & & & \\
\hline Pseudo- $R^{2}$ controls only & 0.25 & & 0.25 & & 0.25 & & .25 & & .25 & \\
\hline Pseudo- $R^{2}$ full model & 0.28 & & 0.25 & & 0.25 & & .30 & & .30 & \\
\hline$n$ & 379 & & 379 & & 378 & & 379 & & 378 & \\
\hline
\end{tabular}

APP, antisocial personality problems.

*Bonferroni $(\alpha=.05) P<.01$.

Finally, Table VII reports the findings for older adolescents (ages 17-19) using the youths' selfreport-based DSM-oriented problems from Wave 1. These models explained between 25.1 and $30.2 \%$ of the variance in self-reported violent behavior for Wave 2. As with earlier models, prior violence served as the strongest predictor of future violence. The separate DSM-oriented models indicated that two of the four DSM-oriented problems (the ADHP scale was omitted for chunk 4 owing to missing scale items for the PHDCN at Wave 1) were significant predictors of future violence. As shown in Model 31 of Table VII, Depressive Problems in late adolescence $(b=.09)$, which represents an adult manifestation of problems similar to the scale for Affective Problems in children and adolescents [Achenbach and Rescorla, 2003], increased the odds of violent crime at Wave 2. A one-unit increase in Depressive Problems increased the odds of violence by $9.7 \%$ (EXP[.093]). As seen in Model 34, Antisocial Personality Problems $(b=.13)$, which is a construct for adults containing many of the same mental health symptoms as ODP and CD in youth, was a significant predictor of future violence. ${ }^{4} \mathrm{~A}$ one-unit

\footnotetext{
${ }^{4}$ To address inherent tautological issues when using a mental health index with items related to criminal offending to predict later offending, we conducted additional ad hoc tests on the APP
}

increase in APP resulted in a $13.4 \%$ (EXP[.126]) increase in the odds of future self-reported violent behavior.

When examining comorbidity for the DSMoriented problems among older adolescents, APP $(b=.115)$ remained a significant predictor of future violence, but the effects of depressive problems were reduced to nonsignificance. A one-unit increase in APP resulted in a $12.2 \%$ (EXP[.115]) increase in the odds of future self-reported violent behavior. For a white, middle class male with no history of violence in chunk 4, the predicted probability of future violent behavior ranged from 7.5 to $20.5 \%$ in the

\section{(footnote continued)}

DSM-oriented scale. Additional logistic regressions were conducted using a modified DSM-oriented scale, with six items excluded that refer to criminal behavior: damaging property, fighting, attacking people, stealing, threatening to hurt people, and doing things to get in trouble with the law. The results revealed no substantive differences in the models for violent crime for age chunk 4 (17-19 years old) with these exclusions in the construct. Indeed, the strength of the relationship between APP and future violence increased slightly in the modified models (separate model: $b=.172, \mathrm{SE}(\mathrm{b})=.045, P<.001$, $\mathrm{OR}=1.188$; comorbidity model: $b=.156, \mathrm{SE}(\mathrm{b})=.052, P=.003$, $\mathrm{OR}=1.169$ ). Although this study was unable to examine change in DSM-oriented constructs within the individual over time owing to space and data limitations here, these findings suggests that the noncriminal traits characterizing ODP during childhood and adolescence may carry over into adulthood and further increase the odds of criminal involvement and poor life course outcomes. 
normal threshold, from 22.4 to $24.5 \%$ in the borderline threshold, and from 26.7 to $67.1 \%$ in the clinical threshold of APP. For a white, middle class male with prior violence, the predicted probability of future violent behavior ranged from 24.3 to $50.3 \%$ in the normal threshold, from 53.2 to $56.0 \%$ in the borderline threshold, and from 58.9 to $88.9 \%$ in the clinical threshold of APP.

\section{DISCUSSION}

This study examined the ability of parent- and youth-based continuous DSM-oriented mental health indicators [Achenbach and Rescorla's, 2001, 2003], to predict the prevalence of self-reported violent behavior within four developmental age chunks. Logistic regression analyses were conducted to look at independent and comorbid effects of the five DSM-oriented scales. The results offer several intriguing observations with regard to the ability of mental health problems to predict offending across cohorts of community-based PHDCN youth. In general, few mental health scales independently and comorbidly predicted future violence. Specifically, when looking across the primary caregiver models for DSM-oriented problems in their children, only 3 out of 15 models examining the individual effects of DSM problems on violence had significant and positive effects, and these were only reported for chunk 1 in children 7-9 years old. However, the independent effects of parent-reported Affective and Anxiety Problems in chunk 1 were subsequently reduced to nonsignificance when controlling for comorbidity in the combined model. Thus, ODP remained as the lone significant predictor of violent crime for this youngest age cohort. Overall, these findings suggest that parent-based indicators of mental health problem for the community-based sample of girls and boys were not robust predictors of future violent behavior. These findings highlight the need for practitioners to gather information across informants when attempting to gauge levels of mental health dysfunction, as different informants may have varying perceptions of problems.

Although the connection between parent-based reports of ODP and youths' self-reported future violence is largely consistent with the literature linking the onset of early oppositional behaviors with violence, especially as it relates to early-starters and lifecourse persistent offenders [Farrington, 1989; Moffitt, 1990], the inability of ODP to explain the continuity of serious offending into either late childhood or early adolescence is somewhat surprising and calls into question the validity of parental assessments of their children's mental health issues. Similar concerns were voiced by Boots [2008] in her work focusing on the ability of DSMoriented problems to predict serious offending over time in the youngest cohort of Pittsburgh Youth Study boys, as "it stands to reason that parents may mitigate their child's behaviors because they may view these problems as reflective of their own dysfunction or failure in parenting" (p 130-131). With respect to developmentally based research, such as that conducted here, scholars have argued persuasively that the use of multiple informants offers a more comprehensive picture of assessment of functioning across domains and situations than a sole informant can provide [Krol et al., 2006]. Indeed, such designs are "essential to preserve the contributions of different informants, even if their reports are not correlated highly" [Renk and Phares, 2004, p 240]. For this reason, this study did not combine measures taken from parents and youths, but rather kept them distinct from one another to allow for such comparisons. Without question, the findings here reemphasize the necessity of considering reports from multiple informants when investigating the origins of problem behaviors, as different informants will view children in various states of functioning depending upon the context and situation [Achenbach, 2005].

In contrast to the parent reports, youth-reported DSM-oriented problems revealed a more consistent picture of issues over various developmental stages. Although only 4 of the 14 separate models of DSMoriented problems reached statistical significance, two of those indicators involved oppositional or adult antisocial problems (ODP for chunk 2 and APP for chunk 4 youths, respectively). Of greater import to the objective of this study is the fact that these oppositional behaviors remained significant across all three cohorts when controlling for comorbid effects, with ODP in older children (10-12 year olds) and young adolescents (13-16 year olds), and Antisocial Personality Problems in young adults (17-19 year olds) at Wave 1 predicting violence at Wave 2. The ability of APP to predict subsequent violence is even more remarkable considering a conservative measure that omitted all crime-related criteria produced consistent results (see note $\# 4$ ). When viewed within a developmental framework, these results imply a continuity of ODP/ APP behaviors from late childhood through young adulthood (from age 10 through 19) that contributes to serious offending. Moreover, the results suggest that mental health issues of affective, anxiety, 
somatic, and ADHP do not contribute to violent pathways, however, oppositional deficits do.

Although this study is exploratory in nature and conducts a relatively simplistic test of DSM-oriented problems at the individual level, these results offer further proof of the appropriateness of using these scales within a developmental framework when considering issues of onset, continuity, and persistence across various life stages. Furthermore, our findings suggest that due caution should be exercised when interpreting the empirical validity of studies that rely upon single measures of mental health problems as sole predictors of offending behaviors. Conversely, combined scales that investigate internalizing or externalizing problems do not always provide a clear picture to practitioners of the best course of action in treating youth with borderline or clinical levels of serious mental health issues that are distinct from one another. In this sense, comorbidity does matter because, if not considered carefully, multiple diagnoses may suggest opposing treatment plans that could be detrimental to influencing longterm outcomes that place youth at risk for violence. Although our study findings must be interpreted with caution and duplicated in other communitybased populations, the implications of these results also highlight the insignificance of comorbidity inasmuch as Oppositional Defiant and Antisocial Personality Problems solely predicted later violence in youth from the ages of 10 through 19 years of age, when controlling for other common mental health disorders, sociodemographics, and earlier violent offending histories.

The results also highlight the clinical and practical implications for using the continuous DSM-oriented mental health scales. On average, a one-unit increase in ODP or APP symptoms resulted in a $20 \%$ increase in the odds of future antisocial behavior, controlling for gender, race, SES, and prior violence. These findings underscore the robustness of ODP/ APP symptoms in predicting violent behavior among youths and the need to examine these effects longitudinally across time points and different stages of human development while taking into account other forms of comorbid mental dysfunction. At a more practical level, the logistic regression analyses allowed for the calculation of predicted probability scores of future violence for each raw score of the DSM-oriented scales. This information offered insight into the benefit of treating mental health problems as continuous constructs. As described in the results section, youths who would be classified as within the "normal" range of ODP and APP problems exhibited high probabilities of future violence. This finding is even more impressive when we consider the non-forensic nature of the sample. In sum, this study suggests that risk detection and prevention methods for antisocial behavior may be improved with careful consideration of borderline levels of serious mental health problems. Such consideration would require the practical use of continuous indicators of mental health problems and less reliance on categorical measures. The results presented here provide further compelling evidence of the utility of continuous measures, such as the DSM-oriented scales created by Achenbach and associates.

Although our findings extend the literature on mental health and developmental criminology by testing the ability of DSM-oriented scales, both individually and in comorbid models, to explain violent offending in a community-based sample of urban youth from the PHDCN, several limitations of this study must be acknowledged. First, many of the composite measures for the DSM-oriented scales demonstrated weak internal consistency (i.e., Cronbach $\alpha$ levels below .70); however, they were retained owing to the body of literature that validates the DSM-oriented scales. More internally consistent constructs may be more likely to create significant effects. Further replication of our study is needed to validate the findings. Second, this study was limited by using relatively simplistic models that do not account for socialization, family factors, peer influences, personality, and community factors that contribute to the genesis of violence over the lifecourse. Also unavailable for inclusion within this study was a measure of substance abuse owing to the limitations within the DSM-oriented scales and PHDCN data. It is also noteworthy that the inclusion of the DSM-related variables yielded only small increases in the amount of explained variance in the model. This fact suggests that the addition of other variables, such as socialization and structural indicators, might improve the models. It is wellestablished that "while causal pathways are complex and prediction at the individual level is problematic, there is evidence that children and young people with multiple risk factors are more likely to have future social problems" [France, 2008, p 3]. Further analyses are necessary to build upon this preliminary work that will utilize more complex methods of analysis (i.e., hierarchical linear modeling) to determine the strength of these DSM-oriented problem behaviors when controlling for other empirically linked risk factors that contribute to antisocial behaviors across different domains and life course stages. 
A notable strength of the PHDCN study is that community-based sampling design and numerous instruments and measures offer researchers a unique opportunity to explore the complex mechanisms related to serious offending with indicators at multiple levels and time points. This study also highlights the utility of adopting more continuous forms of measurement of mental illness when examining the different pathways to aggression across various developmental stages. As this study is limited in that it does not allow for considerations of changes over time within individuals in the cohorts, future studies might also explore the ability of comorbid mental health problems to explain violent offending in these youth at later developmental stages beyond Wave 2. Moreover, this study was unable to test the DSM-oriented scales across more than two time waves of data collection owing to missing data; this type of analysis would be valuable in determining the stability of these mental health problems over time. Additionally, future works should further examine the substantive differences between normal, borderline, and clinical levels of significant mental health problems and the predicted probability of various types of violence or aggression in PHDCN youth, as the dimensional nature of these DSM-oriented problem scales is a tremendous tool for researchers and practitioners when directing precious family and community resources to at-risk youth.

In closing, the findings presented here provide further evidence that oppositional defiance problems play a key role in propelling young people onto pathways that lead to violence and other antisocial outcomes. Contrary to expectations, however, the presence of comorbid mental health problems was not a critical component in predicting violence among PHDCN youth. These conclusions were unexpected and surprising when considering the high number of justice-involved youth flowing into our criminal justice system who are diagnosed with multiple problem behaviors [Grisso, 2008; Loeber, 2004]. Historically, juvenile offenders have been largely underserved with regard to their mental health needs, despite increasing numbers of these youths being assigned a dual diagnosis for substance abuse and comorbid psychiatric disorders [Clingempeel et al., 2008; Grisso, 2008; Teplin et al., 2006]. Numerous studies have shown that juveniles in the criminal justice system have higher rates of mental disorder than their nondelinquent peers [Cocozza, 2002; Vermeiren, 2003]. One explanation for the counterintuitive findings of this study may be the nature of the sample. Indeed, about half the PHDCN is female; as such, it was somewhat unexpected that we would find the robustness and continuity of the oppositional behaviors reported here across the age cohorts in this diversified sample. Because most offenders who have contact with the criminal justice system are male, it is possible that the large proportion of girls diluted the effects of the mental health problems. Future studies should focus on comparison studies across gender. Furthermore, the youth comprise a community-based sample. Again, the effects of mental health problems on violence may have been diluted by the large number of low risk youths, which makes the significant effects of oppositional defiant and antisocial personality problems even more meaningful. Future studies need to replicate these results in other prospective community-based samples to see if these effects are consistent across regions and informants.

\section{ACKNOWLEDGMENTS}

The authors thank the researchers from the Project on Human Development in Chicago Neighborhoods (PHDCN) and ICPSR for access to these data. We also thank the editor and anonymous reviewers for their helpful comments.

\section{REFERENCES}

Achenbach TM. 1991a. Manual for the Child Behavior Checklist/ 4-18 and 1991 Profile. Burlington, VT: University of Vermont, Department of Psychiatry.

Achenbach TM. 1991b. Manual for the Youth Self-Report and 1991 Profile. Burlington, VT: University of Vermont, Department of Psychiatry.

Achenbach TM. 1992. Manual for the Child Behavior Checklist/2-3 and 1992 Profile. Burlington, VT: University of Vermont, Department of Psychiatry.

Achenbach TM. 1997. Young Adult Self Report. Burlington, VT: University of Vermont, Department of Psychiatry.

Achenbach TM. 2005. Later developments. Burlington, VT: University of Vermont, Research Center for Children, Youth, \& Families. Retrieved August 11, 2005, from http://www.aseba.org/ABOUTUS/later_developments.html

Achenbach TM, Edelbrock CS. 1983. Manual for the Child Behavior Checklist and Revised Child Behavior Profile. Burlington, VT: University of Vermont, Department of Psychiatry.

Achenbach TM, Rescorla LA. 2001. Manual for ASEBA School-Age Forms \& Profiles. Burlington, VT: University of Vermont, Research Center for Children, Youth, \& Families.

Achenbach TM, Rescorla LA. 2003. Manual for ASEBA Adult Forms \& Profiles. Burlington, VT: University of Vermont, Research Center for Children, Youth, \& Families.

Achenbach TM, Dumenci L, Rescorla LA. 2003. DSM-oriented and empirically based approaches to constructing scales from the same pool items. J Clin Child Adolesc Psychol 32:328-340. 
American Psychiatric Association. 2000. Diagnostic and Statistical Manual of Mental Disorders, 4th edition, text rev. Washington, DC: American Psychiatric Association.

Angold A, Costello EJ. 1993. Depressive comorbidity in children and adolescents: Empirical, theoretical, and methodological issues. Am J Psychiatry 150:1779-1791.

Angold A, Costello EJ, Erkanli A. 1999. Comorbidity. J Child Psychol Psychiatry 40:57-87.

Arseneault L, Moffitt TE, Caspi A, Taylor PJ, Silva PA. 2000. Mental disorders and violence in a total birth cohort: Results from the Dunedin Study. Arch Gen Psychiatry 57:979-986.

August GJ, Realmuto GM, Joyce T, Hektner JM. 1999. Persistence and desistence of oppositional defiant disorder in a community sample of children with ADHD. J Am Acad Child Adolesc Psychiatry 38:1262-1270.

Bailey BN, Delaney-Black V, Hannigan JH, Ager J, Sokol RJ, Covington CY. 2005. Somatic complaints in children and community violence exposure. Dev Behav Pediatr 26:341-348.

Bardick AD, Bernes KB. 2008. A framework for assessing violent behaviors in elementary school-age children. Children \& Schools 30:83-91.

Barkley RA. 1998. Attention-Deficit Hyperactivity Disorder: A Handbook for Diagnosis and Treatment. New York: Guilford Press.

Bartusch DRJ, Lynam DR, Moffitt TE, Silva PA. 1997. Is age important? Testing a general versus a developmental theory of antisocial behavior. Criminology 35:13-48.

Biederman J, Mick E, Faraone SV, Burback M. 2001. Patterns of remission and symptom decline in conduct disorder: A four-year prospective study of an ADHD sample. J Am Acad Child Adolesc Psychiatry 40:290-298.

Boots DP. 2008. Mental Health and Violent Youth: A Developmental/Lifecourse Perspective. New York: LFB Scholarly Publishing.

Boots DP, Wareham J. 2009. An exploration of DSM-oriented scales in the prediction of criminal offending among urban American youth. Crim Justice Behav 36:840-860.

Capaldi DM, Stoolmiller M. 1999. Co-occurrence of conduct problems and depressive symptoms in early adolescent boys: III. Prediction to young-adult adjustment. Dev Psychopathol 11:59-84.

Clingempeel WG, Britt SC, Henggeler SW. 2008. Beyond treatment effects: Comorbid psychopathologies and long-term outcomes among substance-abusing delinquents. Am J Orthopsychiatry 78:29-36.

Cocozza JJ. 2002. Youth with Mental Health Disorders in the Juvenile Justice System. Juvenile Justice and Mental Health: Proceedings of the Robert Lee Sutherland Seminar XII. Austin, TX: Hogg Foundation for Mental Health.

Conduct Problems Prevention Research Group. 2002. Evaluation of the first 3 years of the Fast Track Prevention Trial with children at high risk for adolescent conduct problems. J Abnorm Child Psychol 30:9-35.

Connor DF. 2002. Aggression and Antisocial Behavior in Children and Adolescents: Research and Treatment. New York: Guilford Press.

Crofford LJ. 2007. Violence, stress, and somatic complaints. Trauma Violence Abus 8:299-313.

Dennis ML, Chan Y, Funk RR. 2006. Development and validation of the GAIN Short Screener (GSS) for internalizing, externalizing and substance use disorders and crime/violence problems among adolescents and adults. Am J Addict 15:80-91.

Elbogen EB, Johnson SC. 2009. The intricate link between violence and mental disorder. Arch Gen Psychiatry 66:152-161.

Farrington D. 1989. Early predictors of adolescent aggression and adult violence. Violence Vict 4:79-100.
Farrington D. 2000. Explaining and preventing crime: The globalization of knowledge. Key note address to the American Society for Criminology. Criminology 38:1-24.

Farrington D. 2005. Integrated Developmental \& Lifecourse Theories of Offending: Advances in Criminological Theory (Vol. 14). New Brunswick, NJ: Transaction Publishers.

Fox J. 1991. Regression Diagnostics. Quantitative Applications in the Social Sciences Series (07-079). Newbury Park, CA: Sage Publications.

France A. 2008. Risk factor analysis and the youth question. J Youth Stud 11:1-15.

France A, Utting D. 2005. The paradigm of "risk and protectionfocused prevention" and its impact on services for children and families. Child Soc 19:77-90.

Frick PJ. 1998. Conduct disorders. In: Ollendick T, Hersen M (eds.). Handbook of Child Psychopathology, 3rd edition. New York: Plenum Press, pp 213-237.

Frick PJ. 2000. A developmental psychopathology approach to understanding and preventing youth violence. J La State Med Soc 152:497-502.

Goldstein NES, Olubadewo O, Redding RE, Lexcen FJ. 2005. Mental health disorders: The neglected risk factor in juvenile delinquency. In: Heidbrun K, Goldstein NES, Redding RE (eds.). Juvenile Delinquency: Prevention, Assessment, and Intervention. New York: Oxford University Press, pp 85-110.

Grisso T. 2008. Adolescent offenders with mental disorders. Future Child 18:143-164.

Hill J, Nathan R. 2008. Childhood antecedents of serious violence in adult male offenders. Aggr Behav 34:329-338.

Kessler RC, Berglund P, Demler O, Jin R, Merikangas KR, Walters EE. 2009. Lifetime prevalence and age-of-onset distributions of DSM-IV disorders in the National Comorbidity Survey Replication. Arch Gen Psychiatry 62:593-602.

Knox M, King C, Hanna GL, Logan D, Ghaziuddin N. 2000. Aggressive behavior in clinically depressed adolescents. J Am Acad Child Adolesc Psychiatry 29:611-618.

Krol NP, De Bruyn EE, Coolen JC, van Aarle EJM. 2006. From CBCL to DSM: A comparison of two methods to screen for DSM-IV diagnoses using CBCL data. J Clin Child Adolesc Psychol 35:127-135.

Lahey BB, Loeber R. 1994. Framework for a developmental model of oppositional defiant disorder and conduct disorder. In: Routh DK (ed.). Disruptive Behavior Disorders in Childhood. New York: Plenum Press, pp 139-180.

Lahey BB, Loeber R, Hart EL, Frick P, Applegate B, Zhang Q, Green SM, Russo MF. 1995. Four-year longitudinal study of conduct disorder in boys: Patterns and predictors of persistence. J Abnorm Psychol 104:83-93.

Langbehn DR, Cadoret RJ, Yates WR, Troughton EP, Stewart MA. 1998. Distinct contributions of conduct and oppositional defiant symptoms to adult antisocial behavior. Arch Gen Psychiatry 55:821-829.

Leschied A, Chiodo D, Nowicki E, Rodger S. 2008. Childhood predictors of adult criminality: A meta-analysis drawn from the prospective longitudinal literature. Can J Criminol Crim 50:435-467.

Lewinsohn PM, Shankman SA, Gau JM, Klein DN. 2004. The prevalence and co-morbidity of subthreshold psychiatric conditions. Psychol Med 34:613-622.

Loeber R. 2004. Delinquency Prevention in a Mental Health Context. Utrecht, Netherlands: Trimbos Institute.

Loeber R, Farrington D. 2000. Young children who commit crime: Epidemiology, developmental origins, risk factors, early interventions, and policy implications. Dev Psychopathol 12:737-762. 
Loeber R, Lahey BB, Thomas C. 1991. Diagnostic conundrum of oppositional defiant disorder and conduct disorder. J Abnorm Psychol 100:379-390.

Loeber R, Farrington D, Stouthamer-Loeber M, van Kammen WB. 1998. Antisocial Behavior and Mental Health Problems: Explanatory Factors in Childhood and Adolescence. Mahwah, NJ: Lawrence Erlbaum Associates.

Loeber R, Burke JD, Lahey BB, Winters A, Zera M. 2000. Oppositional defiant and conduct disorder: A review of the past 10 years, Part I. J Am Acad Child Adolesc Psychiatry 39:1-17.

Loeber R, Burke JD, Lahey BB. 2002. What are adolescent antecedents to antisocial personality disorder? Crim Behav Ment Health 12:24-36.

Mendelson T, Kubzansky LD, Datta GD, Buka SL. 2008. Relation of female gender and low socioeconomic status to internalizing symptoms among adolescents: A case of double jeopardy? Soc Sci Med 66:1284-1296.

Moffitt TE. 1990. Juvenile delinquency and attention deficit disorder: Boys' developmental trajectories from age 13 to age 15. Child Dev 61:893-910

Mrug S, Loosier PS, Windle M. 2008. Violence exposure across multiple contexts: Individual and joint effects on adjustment. AmJ Orthopsychiatry 78:70-84.

Piko BF, Keresztes N, Pluhar ZF. 2006. Aggressive behavior and psychosocial health among children. Pers Individ Diff 40:885-895.

Pliszka SR. 1998. Comorbidity of attention deficit/hyperactivity disorder with psychiatric disorder: An overview. J Clin Psychiatry 59:50-58.

Reiss AJ. 1961. Occupations and Social Status. New York: Free Press.

Renk K, Phares V. 2004. Cross-informant ratings of social competence in children and adolescents. Clin Psychol Rev 24:239-254.

Robins LN. 1966. Deviant Children Growing Up: A Sociological and Psychiatric Study of Sociopathic Personality. Baltimore: Williams \& Watkins.

Russo MF, Beidel DC. 1994. Co-morbidity of childhood anxiety and externalizing disorders: Prevalence, associated characteristics, and validation issues. Clin Psychol Rev 14:199-221.
Sampson RJ. 1997. Collective regulation of adolescent misbehavior: Validation results from eighty Chicago neighborhoods. J Adolesc Res 12:227-244.

Sampson RJ, Raudenbush SW, Earls F. 1997. Neighborhoods and violent crime: A multilevel study of collective efficacy. Science 277:918-924.

Teplin LA. 2001. Assessing Alcohol, Drug, and Mental Disorders in Juvenile Detainees. Office of Juvenile Justice and Delinquency Fact Sheet $\# 02$. Washington, DC: US Department of Justice.

Teplin LA, Abram KM, McClelland GM, Mericle AA, Dulcan MK, Washburn JJ. 2006. Psychiatric Disorders of Youth in Detention. US Department of Justice, Office of Justice Programs. Washington, DC: US Government Printing Office.

Tremblay RE, Pagani-Kurtz L, Masse LC, Vitaro F, Pihl RO. 1995. A bi-modal preventive intervention for disruptive kindergarten boys: Its impact through mid-adolescence. J Consult Clin Psychol 63:560-568.

Troop-Gordon W, Ladd GW. 2005. Trajectories of peer victimization and perceptions of the self and schoolmates: Precursors to internalizing and externalizing problems. Child Dev 75: 1072-1091.

US Department of Health and Human Services. 1999. Mental Health: A Report of the Surgeon General. Rockville, MD: US Department of Health and Human Services.

Vermeiren R. 2003. Psychopathology and delinquency in adolescents: A descriptive and developmental perspective. Clin Psychol Rev 23:277-318.

Widiger TA, Clark LE. 2000. Toward DSM-V and the classification of psychopathology. Psychol Bull 12:946-963.

Wittchen H, Lieb R, Pfister H, Schuster P. 2000. The waxing and waning of mental disorders: Evaluating the stability of syndromes of mental disorders in the population. Compr Psychiatry 41:122-132.

Zoccolillo M, Pickles A, Quinton D, Rutter M. 1992. The outcome of childhood conduct disorder: Implications for defining adult personality disorder and conduct disorder. Psychol Med 22:971-986. 